\title{
$\mathrm{DES}$ 키 확장을 이용한 가변 $\mathrm{P}$ box 생성에 관한 연구
}

\author{
이 준 $^{+}$ \\ 요 약
}

$\mathrm{DES}$ 확장키를 이용하여 가변 P box를 생성하고 이용하는 블록암호를 제안하였다. 매 라운드마다 가변 P box를 구현할 때 효율적으로 실행 할 수 있는 방안도 제시하였다. 차분 공격과 선형 공격에 관한 반례를 제시함으로 제안된 알고리즘이 기존의 두 공격으로부터 안전함을 보였 다. 제안된 알고리즘과 3 중 $\mathrm{DES}(3 \mathrm{DES}$ )에서 사용되는 실 키 길이 비교는 전수공격 측면에서 제안된 알고리즘이 $3 \mathrm{DES}$ 보다 더 안전함을 보인 다. $3 \mathrm{DES}$ 와 제안된 알고리즘의 컴퓨터 실험 결과 암호처리 속도측면에서 제안된 알고리즘이 $3 \mathrm{DES}$ 보다 3 배정도 빠름을 보였다.

키워드 : DES, 키 확장, 가변 $\mathrm{P}$ box

\section{A Study on a Variable P box Generation Using a DES Key Expansion}

\author{
Jun $\mathrm{Lee}^{+}$
}

\begin{abstract}
Using an expanded DES key, we suggest a block cipher algorithm to generate and to use a variable $\mathrm{P}$ box. We also present an efficient way for the implementation of variable P box at each round. Using counter examples on Differential Cryptanalysis(DC) and Linear Cryptanalysis(LC), we show that the suggested algorithm is strong enough to overcome those attacks. Compared with the real key bits of triple DES(3DES), the new algorithm is much safer in the points of the exhaustive attack. The results of computer simulations show that the new algorithm is almost 3 times faster than 3DES regarding the cipher process time.
\end{abstract}

Keywords : DES, Key Expansion, Variable $P$ box

\section{1. 서 론}

현대 블록 암호는 112 비트 이상의 키 길이에 대해 안전함 을 주장한다[1]. DES는 가장 많이 사용되는 블록암호이나, 키 길이가 64 비트로 현대 블록 암호가 요구하는 키 길이에 비해 짧은 문제점을 갖고 있다. 또한 그 중 8비트를 사용하 지 않아 스스로 키 공간을 축소시킴으로 다양한 공격의 가 능성을 제공하였다. 환경적으로 계산 능력 향상, 공격 방법 의 개발 등으로 전수 공격보다 적은 노력으로 $\mathrm{DES}$ 암호문 해독이 가능함을 보였다[2][3].

일반적으로 잘 알려진 $\mathrm{DES}$ 공격은 차분 공격 (Differential Cryptanalysis)과 선형 공격(Linear Cryptanalysis)으로 전수 공격보다 적은 경우의 수로 키를 추측할 수 있다. 공격 방 법은 주로 $\mathrm{DES}$ 의 비선형 부분에 대한 연구이며, 키 추측 가능성을 합리적으로 제시한다. 또한 이들의 연구에서 선형 부분은 수학적으로 쉬운 부분으로 간주하여 공격범위에 포

† 종신회원 : 공군사관학교 전산학과 교수

논문접수: 2011년 2월 15일

수 정 일 : 1 차 2011년 5월 27일

심사완료: 2011년 5월 31일
함하지 않았다. 하지만 선형 부분 P box도 라운드 별로 비 공개되는 가변 상황을 $\mathrm{DES}$ 에 적용한다면 공격이 쉽지 않음 을 보일 수 있다.

본문 구성은 2절에서 $\mathrm{DES}$ 공격 관련 연구에서 공격이 검토되지 않은 새로운 암호화 가능성을 언급하고, 가변 $\mathrm{P}$ box 알고리즘을 3절에서 제안하였다. 4절은 제안된 알고리 즘의 안전성을 차분 공격과 선형 공격 가정에 대한 반례를 제시함으로 전수 공격 외에는 다른 공격이 가능하지 않음을 보였고, 5 절에서 제안 알고리즘은 $\mathrm{DES}$ 실행 시간의 $10 \%$ 정 도 추가되며, 전수공격 측면 암호화 강도는 Triple $\mathrm{DES}$ (이 하 $3 \mathrm{DES})$ 보다 훨씬 안전하며, 효율성은 $3 \mathrm{DES}$ 에 비해 3 배 빠름을 컴퓨터 실험으로 보였다.

논문에 사용될 기호를 다음과 같이 정의한다.

- $C(A, B)$ 원소별 5비트 Full Adder 연산, $A, B$ 및 $C(A, B)$ 는 차원이 같은 행렬

- $P$ 는 DES의 $\mathrm{P}$ box로 $1 \times 32$ 행렬

- $P[k]$ 는 키 $k$ 로부터 변형된 $P$ box

- One는 모든 원소가 1 인 $1 \times 32$ 행렬 
- $e_{i}$ 는 $(i+1)$ 번 원소가 1 이고 나머지 원소가 0 인 $32 \times 1$ 단위 열벡터, $0 \leq i \leq 31$

- $P_{k e y}$ 는 가변 P box 생성에 사용될 확장키 64비트

\section{2. 관련 연구}

\section{1 차분 공격}

Biham과 Shamir에 의해 제안된 선택 평문 공격으로 입 력 차분에 대한 출력 차분을 이용하여 키의 특정 비트를 추 론할 수 있다[4]. 의도하는 입력 차분에 대한 출력 차분을 충분히 확보할 수 있음을 가정한다. 특정한 비트에 대한 입 력 차분에 대해 출력 차분 발생 확률 특성을 이용하여 키를 추론할 수 있다. 차분 공격은 비선형 부분 연구에 집중되었 다. 선택 평문 공격에 대한 $\mathrm{DES}$ 의 차분 공격 기본 가정은 선형 부분인 $\mathrm{P}$ box가 고정된 상태로 특정 모델의 라운드를 완료하였을 때 입출력 차분 모델을 확률적으로 추론하여 전 수 공격보다 적은 경우의 공격으로 키를 찾는다. 만약 $\mathrm{P}$ box를 라운드 별로 가변으로 설정한 후 가변 내용을 공개하 지 않을 경우 입출력 차분에 대한 모델의 확률적 특성은 성 립하지 않는다.

\section{2 선형 공격}

Matsui에 의해 제안된 기지 평문 공격으로 입력 비트, 출 력 비트 및 키 비트에 대한 관계를 정리한 선형식의 확률적 특성을 이용하여 키를 추측한다[5]. 특정 라운드로 구성된 모델의 특징을 이용하여 키, 평문, 암호문의 선형 관계식을 유도한다. S box에 적용되는 키와 입출력문의 관계를 편차 특성을 이용한 확률로 선형식을 유도한다. 선형 공격 역시 Feistel 구조의 각 라운드에서 선형사상 되는 비트 위치가 고정된 특성을 이용한다. $\mathrm{DES}$ 에서 $\mathrm{P}$ box가 확장된 개인키 에 의해서 라운드 별로 비공개 가변으로 정의될 경우 매 라 운드 마다 S box의 출력이 비트별로 선형 사상되는 위치는 예측할 수 없게 된다. 이 경우 선형공격에서 유도되는 선형 식은 무의미하다.

$\mathrm{DES}$ 공격은 $\mathrm{P}$ box를 고정시킨 상태에서 선택평문 공격 과 기지평문 공격을 고려하였다. 따라서 라운드 별 비공개 가변되는 선형 사상을 $\mathrm{P}$ box 위치에 적용할 경우 기존의 공격에 대한 특성은 성립되지 않는다.

$\mathrm{DES}$ 의 대표적인 두 가지 공격에서 기본가정은 비선형 부분 $\mathrm{S}$ box와 선형 부분 $\mathrm{P}$ box가 공개되어 공격자가 구조 를 파악할 수 있음이다. 이에 대한 대책은 $\mathrm{S}$ box를 변경하 는 재설계 방안[6][7][8][9]을 다양하게 제안하고 있으나 그 에 따른 문제점[10]도 지적되고 있다. 따라서 공개된 S box 의 재설계로는 공격에 대한 문제점을 완전히 해결할 수 없 으며 암호함수 자체를 수정하는 것이 바람직하다고 판단된 다. 다음과 같이 제시되는 가변 P box도 암호함수 자체를 수정하는 방식이 될 수 있다.
만일 $\mathrm{P}$ box가 $\mathrm{DES}$ 의 확장키 $P_{k e y}$ 에 따라 라운드별 비 공개 가변으로 선형 사상할 수 있다면, $P_{k e y}$ 를 소유하지 않 은 제 3 자는 라운드마다 변하는 P box를 형성할 수 없다. 이는 가변 $\mathrm{P} \mathrm{box}$ 를 이용하여 기존 공격을 방지하는 대책이 될 수 있다. 또한 $P_{k e y}$ 의 이용은 현대 블록 암호가 안전성 을 요구하는 이상의 키 길이 확장 문제도 해결할 수 있다.

\section{3. 제안 알고리즘}

$\mathrm{DES}$ 에서 비공개 가변 $\mathrm{P}$ box 이용 알고리즘을 다음과 같 이 제안한다.

\section{1 가변 P box}

1) 가변 P box 조건

(1) 0부터 31로 중복 없이 구성된다.

(2) $P_{k e y}$ 부터 생성된 $n$ 비트 라운드 키 $k_{i}$ 에 의해서 가변 $\mathrm{P}$ box가 구성된다.

(3) 가변 P box 생성시간은 암호화에 영향이 거의 없어야 한다.

\section{2) 가변 P box 제안}

라운드마다 가변 $\mathrm{P}$ box를 생성하는 방법 중 하나는 $P_{k e y}$ 로부터 유도된 라운드 키 $k_{i}$ 를 seed로 하여 0부터 31 까지 중복 없이 생산되는 난수로 구성하는 것이다. 이 방법 은 $\mathrm{DES}$ 에 난수 발생 알고리즘을 추가하는 부담이 있으며, 암호화 시간보다는 라운드마다 중복이 없는 가변 P box 생 성 시간이 더 많이 소요되므로 비현실적이다.

가능한 다른 방법은 $\mathrm{P} \mathrm{box}$ 의 구성 원소에 대해 라운드마 다 동일한 키 값 $k_{i}$ 를 5 비트 Full Adder 연산 후 carry를 무시한 5비트 sum을 원소로 가변 P box를 구성한다. 이 방 법은 가변 P box의 생성과정에서 추가조치 없이 원소 중복 을 방지할 수 있으며, 라운드 키에 의해 생성되는 조건 등 을 만족한다. 라운드 키 $k_{i}$ 로부터 재구성 된 가변 $\mathrm{P}$ box인 $P\left[k_{i}\right]$ 는 다음과 같다.

$$
P\left[k_{i}\right]=C\left(P, k_{i} \text { One }\right)
$$

이 경우 $P$ 의 $j$ 번 원소를 $p_{j}$ 라 할 때 $P\left[k_{i}\right]$ 의 $j$ 번 원소 는 수학적으로 $\left(p_{j}+k_{i}\right) \operatorname{Mod} 32$ 가 된다. 예를 들면 $k_{i}=11$ 은 라운드 키에 의해서 $P$ 가 <표 $1>$ 과 같이 변한다.

〈표 1〉 $P[11]$

\begin{tabular}{|c|c|c|c|c|c|c|c|}
\hline 26 & 17 & 30 & 31 & 7 & 22 & 6 & 27 \\
\hline 11 & 25 & 1 & 4 & 15 & 28 & 9 & 20 \\
\hline 12 & 18 & 2 & 24 & 10 & 5 & 13 & 19 \\
\hline 29 & 23 & 8 & 16 & 0 & 21 & 14 & 4 \\
\hline
\end{tabular}


<표 1>의 $P[11]$ 은 라운드 키 $k_{i}$ 에 의해서 0 부터 31 까 지 중복 없이 비트의 위치를 지정한다.

이 방법은 난수 발생기로 가변 $\mathrm{P}$ box를 만드는 것보다 효율적이나 매 라운드마다 5 비트 Full Adder 덧셈 연산 32 회가 요구되며, 하드웨어 구성은 32개의 5 비트 Full Adder 가 라운드마다 필요하므로 효율적이라 할 수 없다. S box 처리된 32비트 $R$ 에 대해 다음과 같은 $k_{i}$ 비트 circular shift left 연산 1 회로 동일한 결과를 얻을 수 있다.

3) Circular shift left

$\mathrm{S}$ box에 의해서 처리된 32 비트 $R$ 과 $P$ 는 다음과 같이 표시된다.

$$
\begin{gathered}
R=\left[r_{0}, r_{1}, \cdots, r_{30}, r_{31}\right] \\
P=\left[e_{p_{0}}, e_{p_{1}}, \cdots, e_{p_{30}}, e_{p_{31}}\right]
\end{gathered}
$$

$R$ 에 대한 $\mathrm{P}$ box 선형 사상은 비트 위치를 다음과 같은 $R P$ 로 바꾼다.

$$
R P=\left[r_{p_{0}}, r_{p_{1}}, \cdots, r_{p_{30}}, r_{p_{31}}\right]
$$

라운드 $i$ 에서 라운드 키 $k_{i}$ 를 적용한 가변 $P\left[k_{i}\right]$ 는 다음 과 같이 표시할 수 있다.

$$
P\left[k_{i}\right]=\left[e_{C\left(p_{0}+k_{i}\right)}, e_{C\left(p_{1}+k_{i}\right)}, \cdots, e_{C\left(p_{31}+k_{i}\right)}\right]
$$

그리고 $\mathrm{S}$ box에 의해 처리된 $R$ 을 $P\left[k_{i}\right]$ 로 선형 사상하 여 비트 위치를 변환시킨 $R P\left[k_{i}\right]$ 는 다음과 같다.

$$
R P\left[k_{i}\right]=\left[r_{C\left(p_{0}+k_{i}\right)}, r_{C\left(p_{1}+k_{i}\right)}, \cdots, r_{C\left(p_{31}+k_{i}\right)}\right]
$$

$\mathrm{S}$ box에 의해 처리된 $R$ 을 왼쪽으로 $n$ 비트 왼쪽 순환 시프트 한 결과를 $R(n)$ 이라 하자.

$$
\begin{aligned}
& R(n)=\left[r_{n}, r_{n+1}, \cdots, r_{31}, r_{0}, r_{1}, \cdots, r_{n-1}\right] \\
& =\left[r_{C(0, n)}, r_{C(1, n)}, \cdots, r_{C(30, n)}, r_{C(31, n)}\right]
\end{aligned}
$$

$R(n)$ 에 $P$ 를 적용한 결과는 다음과 같다.

$$
R(n) P=\left[r_{C\left(p_{0}+n\right)}, r_{C\left(p_{1}+n\right)}, \cdots, r_{C\left(p_{31}+n\right)}\right]
$$

위의 결과에서 $n=k_{i}$ 를 적용하면 $R P\left[k_{i}\right]$ 와 $R\left(k_{i}\right) P$ 는 동일한 결과를 얻는다. 라운드 키 $k_{i}$ 로 $P\left[k_{i}\right]$ 를 얻기 위 해 매 라운드마다 32 개의 5비트 Full Adder 연산을 실시하 는 대신 $\mathrm{S}$ box 처리된 결과 $R$ 에 대해 라운드 키 $k_{i}$ 만큼 왼쪽 순환 시프트 한 후 $R\left(k_{i}\right)$ 에 $P$ 를 적용하면 $R P\left[k_{i}\right]$
와 동일한 결과를 얻을 수 있다.

이는 64비트 암호문 처리에 512번의 5비트 Full Adder 연 산으로 얻는 결과 대신 $R$ 을 16 번 왼쪽 순환 시프트로 처리 하여 동일한 결과를 효율적으로 얻을 수 있음을 의미한다.

\section{$3.2 P_{k e y}$ 구성}

5비트 Full Adder 이용 알고리즘에서 각 라운드마다 가 변시키는 키 $k_{i}$ 의 범위는 5 비트 이하이다. 이 경우 DES는 16 라운드로 구성되었으므로 기본키 64비트 외에 확장키 80 비트가 필요하다. 소프트웨어 측면에서 변수는 $8,16,32,64$ 비트로 구성되므로 $k_{i}$ 는 라운드 당 5 비트보다는 4 비트로 구 성하는 것이 암호화 및 복호화 알고리즘 키 구성에 효율적 이다. 5 비트를 사용할 경우 전수 공격에 대한 암호화 강도 는 4비트보다 크지만, 4 비트도 공격으로부터 안전하다 가정 할 경우 암호화 및 복호화 절차에 대한 프로그래밍의 효율 성을 고려하여 라운드 키를 4 비트로 제안한다.

\section{3 알고리즘}

제안 알고리즘은 64비트 메시지 입력에 대한 $\mathrm{DES}$ 암호 알고리즘과 유사하다. 차이점은 입력키 부분에서 기본키 $k e y$ 외에 확장키 $P_{k e y}$ 가 추가되었다. $\mathrm{P}$ box 원소에 대해 5 비트 Full Adder로 처리하는 가변 과정을 S box 처리된 32 비트 $R$ 에 대해 왼쪽 순환 시프트를 적용하는 절차로 대 체하여 높은 효율성을 구현한다. <표 2>의 $\mathrm{DES}$ 알고리즘 에 다음과 같이 $R$ 의 왼쪽 순환 시프트를 추가함으로 가변 $\mathrm{P}$ box 대체 효과를 얻는다.

\section{Circular_shift( $\& R$, round, $\left.P_{k e y}\right)$;}

$P_{k e y}$ 는 64비트이며 round마다 4비트씩 키 $k_{i}$ 를 생산한 다. $\mathrm{S}$ box에서 처리된 $R$ 을 $k_{i}$ 비트 왼쪽 순환 시프트 시킨 후 $P$ 를 적용하면, $R$ 에 가변 $P\left[k_{i}\right]$ 를 적용한 것과 동일한 결과를 얻는 알고리즘이다.

〈표 2〉 제안 알고리즘

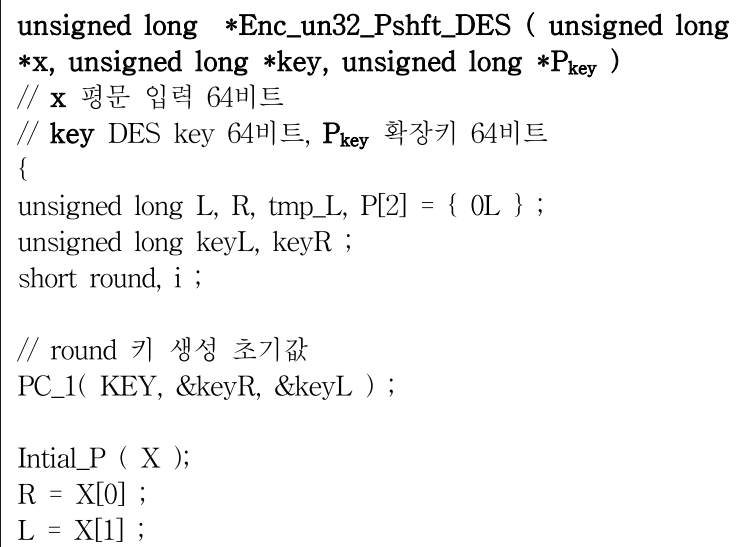




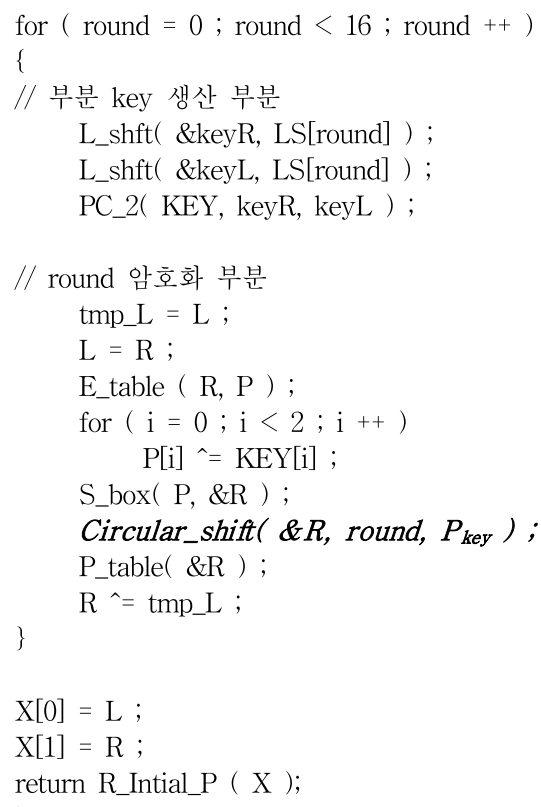

\section{4. 안전성 검토}

제안된 알고리즘에 대해 차분 공격과 선형 공격 기본 모 델을 적용하여 안전성을 검토한다.

\section{1 차분 공격}

차분 공격은 선택평문 공격을 가정한다. 따라서 원하는 입력에 대한 출력 차분도 얻을 수 있다. $k e y$ 의 특정 비트 를 찾기 수월한 입력 차분을 가정하고 그에 대한 출력 차분 을 얻는다. (그림 1)의 1 라운드 특성은 14/64 확률로 입력 차분에 대한 출력 차분의 관계가 성립된다[4].

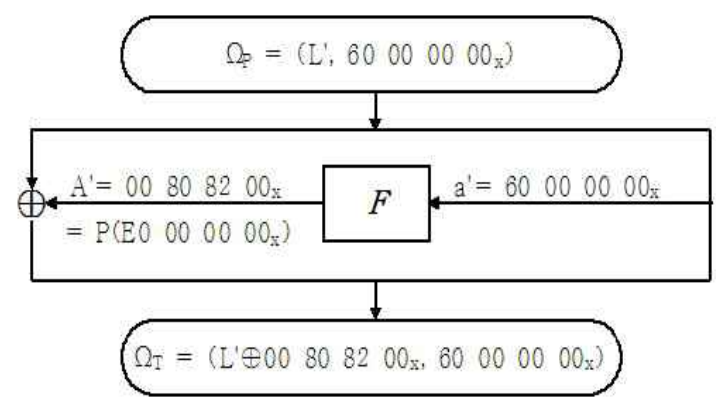

(그림 1) one round characteristic

제안된 알고리즘과 같이 $\mathrm{P}$ box를 라운드 별로 키에 따라 가변인 경우 (그림 1)과 같은 고정된 $\dot{A}$ 을 얻을 수 없다. 예 를 들면 라운드 1 에서 라운드 키 $k_{1}$ 가 1 인 경우 $\mathrm{P} \mathrm{box}$ 는 $P[1]$ 이 되며 $F$ 처리된 후 값은 다음과 같다.

$$
\dot{A}=P[1]\left(E 0000000_{x}\right)=00808800_{x}
$$

만일 $k_{1}$ 이 2 인 경우 $F$ 처리된 후 값은 다음과 같다.

$$
\dot{A}=P[2]\left(E 0000000_{x}\right)=00820800_{x}
$$

라운드 키 $k_{1}$ 값에 따라 출력 차분 $A$ 이 변화한다.

(그림 2)에서 제시하는 예제 역시 $\mathrm{P}$ box가 고정된 경우 에 $1 / 16$ 확률로 입력 차분에 대한 출력 차분 특성을 얻을 수 있다[4]. (그림 1)과 같은 라운드 키 $\left(k_{i} \neq 0, i=0,1,2\right.$ )에 의한 가변 P box를 적용할 경우 $\dot{A} \neq 00200008_{x}$ 이다. 연쇄적인 결과로 $\dot{b} \neq 0_{x}, \quad \dot{B} \neq 0_{x}$ 이 되며, $\dot{c} \neq 00000400_{x}$ 와 $\dot{C} \neq 00200008_{x}$ 된다. 따라서 $\Omega_{T}^{2}$ 는 의도된 출력 차분을 얻을 수 없다. 제안된 알고리즘과 같이 $\mathrm{P}$ box가 라운드 키에 따라 가변되는 경우 어떠한 선택 평 문 공격에 대해서 적당한 확률로 입력 차분에 대한 출력 차 분을 유도할 수 없다. 라운드 별로 가변 $\mathrm{P} \mathrm{box}$ 를 적용시킨 입출력 차분에 대해서 $\mathrm{DC}$ table은 의미를 가질 수 없으므로 차분 공격 가능한 모델을 만들 수 없다. 따라서 모든 라운 드에 비공개 가변 $\mathrm{P}$ box를 적용한 경우 차분 공격은 불가 능하다.
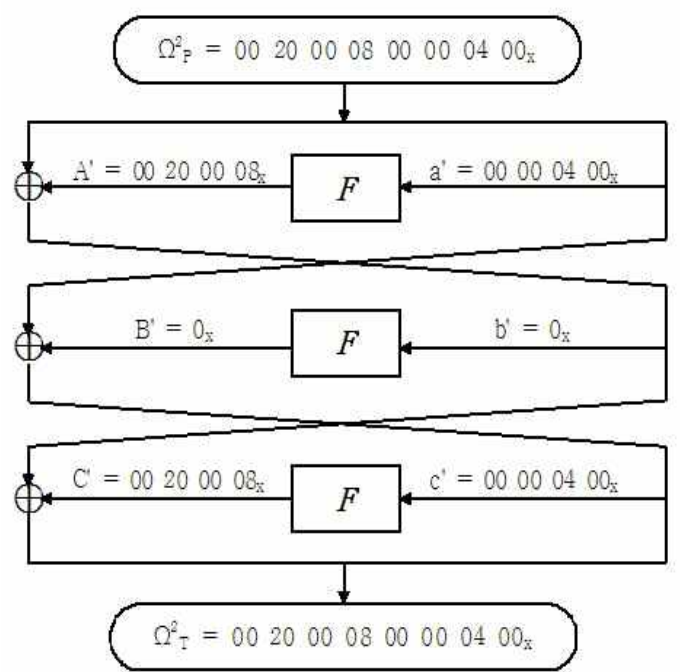

(그림 2) 3 round characteristic

4.2 선형 공격

선형공격은 무작위로 제시된 평문과 대응하는 암호문 및 키에 대해 유의 확률 $p$ 로 다음과 같은 선형 근사식을 구성 한다. 기호와 예문은 Matsui 논문[5]을 인용한다.

$$
P\left[i_{1}, i_{2}, \cdots, i_{a}\right] \oplus C\left[j_{1}, j_{2}, \cdots, j_{b}\right]=K\left[k_{1}, k_{2}, \cdots, k_{c}\right]
$$


(그림 3)에서 제 1 단의 $\mathrm{F}$ 함수에 식을 적용하면 12/64 확률로 다음 식들이 성립한다.

$$
\begin{aligned}
& X_{2}[7,18,24,29] \oplus P_{H}[7,18,24,29] \oplus P_{L}[15] \\
& =K_{1}[22] \\
& X_{2}[7,18,24,29] \oplus C_{H}[7,18,24,29] \oplus C_{L}[15] \\
& =K_{3}[22]
\end{aligned}
$$

위 두 식에서 $\mathrm{X} 2$ 를 소거하면

$P_{H}[7,18,24,29] \oplus C_{H}[7,18,24,29] \oplus P_{L}[15]$

$\oplus C_{L}[15]=K_{1}[22] \oplus K_{3}[22]$

이러한 관계에 대해 제안된 알고리즘을 적용하여 라운드 1 과 3 에 키 $k_{1}$ 과 $k_{3}$ 를 각각 적용할 경우 식은 다음과 같다.

$$
\begin{aligned}
& X_{2}\left[C\left(7, k_{1}\right), C\left(18, k_{1}\right), C\left(24, k_{1}\right), C\left(29, k_{1}\right)\right] \oplus \\
& P_{H}\left[C\left(7, k_{1}\right), C\left(18, k_{1}\right), C\left(24, k_{1}\right), C\left(29, k_{1}\right)\right] \oplus \\
& P_{L}[15]=K_{1}[22] \\
& X_{2}\left[C\left(7, k_{3}\right), C\left(18, k_{3}\right), C\left(24, k_{3}\right), C\left(29, k_{3}\right)\right] \oplus \\
& C_{H}\left[C\left(7, k_{3}\right), C\left(18, k_{3}\right), C\left(24, k_{3}\right), C\left(29, k_{3}\right)\right] \oplus \\
& C_{L}[15]=K_{3}[22]
\end{aligned}
$$

만일 $k_{1} \neq k_{3}$ 경우 $X_{2}$ 는 소거될 수 없다. 또한 $k_{1}=k_{3}$ 이라도 평문과 암호문의 정확한 비트 위치를 파악

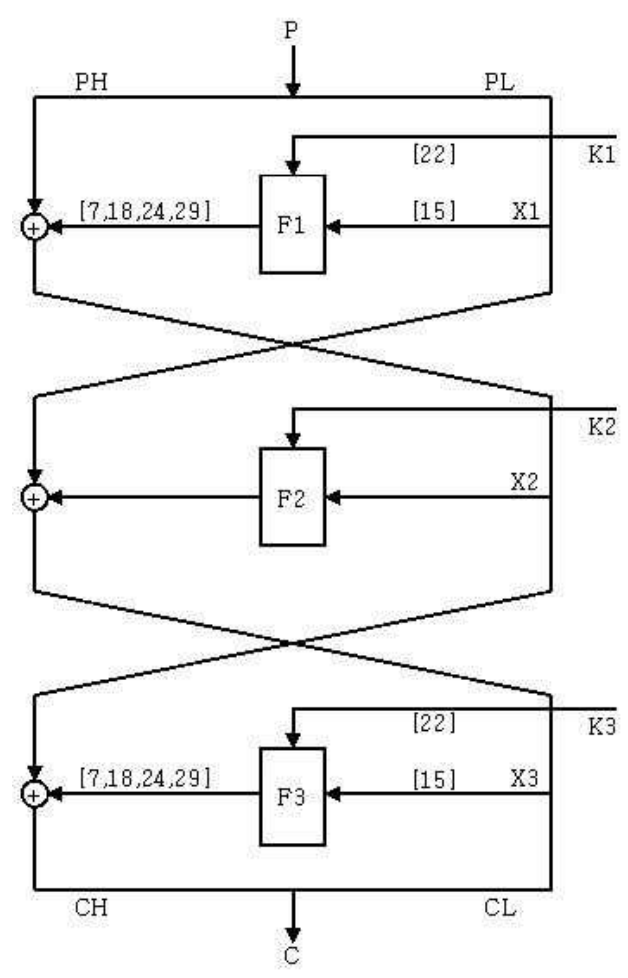

(그림 3) 3-round DES cipher
은 곤란하다. 이와 같이 간단한 3 단 $\mathrm{DES}$ 에 대해서도 가변 $\mathrm{P}$ box를 적용할 때 입력 평문과 출력 암호문 및 키 관계를 설정할 수 있는 최량 표현은 불가능하다. 따라서 모든 라운 드에 비공개 가변 $\mathrm{P}$ box를 적용할 경우 선형 공격은 불가 능하다.

\section{5. 실 험}

64비트 메시지 $\mathrm{M}$ 에 대해 암호화 및 복호화 알고리즘 정 확성과 효율성을 다음과 같이 측정하였다.

\section{1 실험 일반}

실험에 사용된 알고리즘들은 $\mathrm{C}++$ 로 작성하였다. 암호화 및 복호화 과정은 업무용 $\mathrm{PC}$ 에서 실행하였다. $\mathrm{PC}$ 성능은 Intel Atom CPU 230, 1.6GHz, 0.99 GB RAM이다.

$\mathrm{DES}$ 암호화 최소 블록단위 64 비트 $\mathrm{M}$ 에 대한 암호화 및 복호화 시간을 측정하였다. 임의로 선택한 64 비트 메시지 $\mathrm{M}$ 은 다음과 같다.

$\mathrm{M}=\left\{65,66,67,68,69,{ }^{\prime} \mathrm{F}^{\prime}, \mathrm{I}^{\prime}, \mathrm{I}^{\prime}\right\}$

실험은 알고리즘 $\mathrm{DES}, 3 \mathrm{DES}$ 및 제안 알고리즘 3 개를 구현한 후 각 알고리즘의 정확성 확인과 메시지 $\mathrm{M}$ 의 암호 화 및 복호화 과정 시간측정으로 효율을 비교하였다.

\section{2 실험 결과}

세 암호화 알고리즘은 $\mathrm{M}$ 에 대해 암호화/복호화 과정에서 동일한 $\mathrm{M}$ 을 생산하였다.

$\mathrm{DES}$ 의 암호화 및 복호화 시간은 대단히 짧아 1 회 측정 으로 정확한 값을 얻을 수 없다. 64 비트 M에 대한 암호화/ 복호화 과정을 1000 만 번 반복하여 각 알고리즘에 대한 암 호화/복호화 실행 평균시간을 <표 $3>$ 과 같이 얻었다.

〈표 3〉효율성 비교(시간 $\mu-\mathrm{sec}$ )

\begin{tabular}{|c|c|c|c|}
\hline 구 분 & 시간 & 키 길이 & 실 키 길이 \\
\hline $\mathrm{DES}$ & 52 & 64 & 56 \\
\hline $3 \mathrm{DES}$ & 168 & 128 & 112 \\
\hline 제안 DES & 58 & 128 & 120 \\
\hline
\end{tabular}

$\mathrm{DES}$ 와 $3 \mathrm{DES}$ 의 암호화 및 복호화 시간비교에서 효율성 은 라운드 수에 의존함을 알 수 있다. 제안 알고리즘은 라 운드마다 가변 $\mathrm{P}$ box 생성과 동일한 효과를 주는 왼쪽 순 환 시프트에 약 $10 \%$ 시간이 추가되었다. 이는 $3 \mathrm{DES}$ 보다 훨씬 적은 시간이 소요되며, $\mathrm{DES}$ 시간과 유사하다. 또한 실 험결과 제안된 알고리즘은 다음과 같이 요약 할 수 있다.

(1) $\mathrm{DES}$ 는 차분 공격과 선형 공격에 취약점이 있으나 제안 
된 알고리즘은 차분 공격과 선형 공격모델이 적용될 수 없다.

(2) $3 \mathrm{DES}$ 의 실 키 길이는 112 비트이나 제안된 알고리즘의 실 키 길이는 120 비트로 전수 공격에 더 강하다.

(3) 제안 알고리즘의 암호화 속도측면에서 효율성은 $\mathrm{DES}$ 와 유사하며 3DES보다 약 3 배 빠르다.

\section{6. 맺음말}

본 연구는 확장된 $\mathrm{DES}$ 키로부터 각 라운드에 사용되는 $\mathrm{P}$ box를 비공개 가변 형태로 효율적으로 변형할 수 있는 알고리즘을 제안하였다. 5비트 Full Adder 연산 대신 S box 처리된 32비트를 왼쪽 순환 시프트 시킴으로 동일한 효과가 있음을 보인 후 이 부분을 $\mathrm{DES}$ 알고리즘에 적용 하였다. 제 시된 가변 $\mathrm{P}$ box 생성은 키에 의존하므로 확장키가 다를 경우 입력과 출력에 대한 고정된 분석이 불가능하다. 따라 서 차분 공격과 선형 공격 가능한 모델을 제시할 수 없음을 보이면서 기존의 공격에 대해 안전함을 보였다.

또한 컴퓨터 실험을 통해 제안된 알고리즘이 $3 \mathrm{DES}$ 보다 약 3 배 정도 빠르며, $\mathrm{DES}$ 성능과 유사한 시간이 요구되지 만 암호화 강도는 전수 공격을 가정할 경우 $3 \mathrm{DES}$ 보다 훨씬 좋음도 보였다. 제안된 알고리즘은 키를 제외한 모든 과정 이 공개되는 Kerckhoffs 조건[11]을 모두 만족하는 블록 알 고리즘이다.

\section{참 고 문 헌}

[1] 홍성룡, 조정호, "SDR System 적용을 위한 한국형 알고리즘 (SEED) 구현 및 성능분석”, 한국정보과학회 2003년 봄 학술발 표 논문집 제 30 권 제 1 호, pp.319-321, 2003. 4.

[2] E. Biham and A. Shamir "Differentila Cryptanalysis of the full 16 round DES”, Crypto'92 Extended Abstracts, 1992.

[3] M. Matsui. "Linear Cryptanalysis of DES Cipher(I)", SCIS93-3C, Jan., 1993.
[4] E. Biham and A. Shamir "Differentila Cryptanalysis of DES like Crypto systems", Jour. of CRYPTOLOY, Vol.4, No.1, 1991.

[5] M Matsui, "Linear Cryptanalysis Method for DES Cipher", Abstracts of EUROCRYPT'93, pp.W112-W123, May, 1993.

[6] E. Biham and A. Shamir "Differentila Cryptanalysis of FEAL and N-hash", technical report, Weizmann Institute of Science, Israel, 1991.

[7] H. Fiestel, "Cryptography and Computer Privacy", Science America, Vol.228, No.5. 1973.

[8] J. B. Kam and G. I. Davida, "Structured Design of Substitution Permutation Encryption Network", IEEE Tran. on Computer, Vol.C-28, No.10, Oct., 1979.

[9] M. H. Deason and S. E. Tavares, "An Expanded Set of S box Design Criteria based on information theory and its Relation to differential-Like attacks" Proc. of EUROCRYPTO'91, Springer-Verlag, 1991.

[10] L. Brown, M. Kwan, J. Pieprzyk and J. Seberry, "Improving Resistance to Differential Cryptoanalysis and Redesign of LOKI", Abstract of ASIACRYPT'91, 1991.

[11] Mark Stamp, "Information Security-Principles and Practice", Wiley, 2005
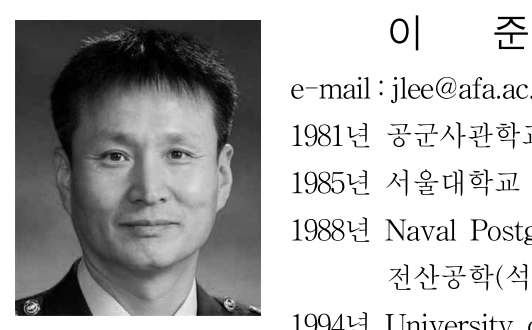

e-mail : jlee@afa.ac.kr

1981년 공군사관학교

1985년 서울대학교 수학과

1988년 Naval Postgraduate School 전산공학(석사)

1994년 University of Florida 전산공학(박사)

1989년 현 재 공군사관학교 전산학과 교수 관심분야 : 암호알고리즘 